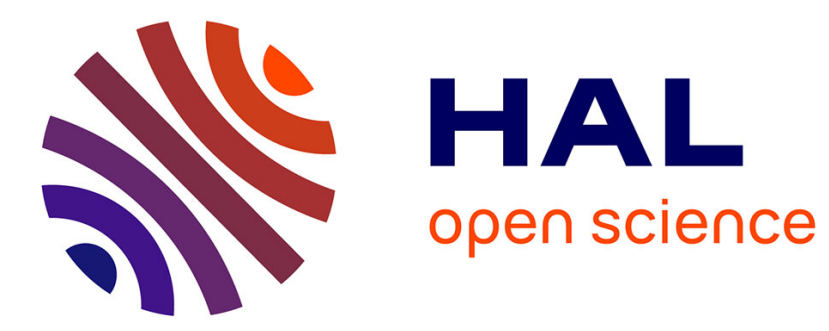

\title{
A study by In Situ FTIR Spectroscopy of the Decomposition of Precursors for the MOCVD of High Temperature Superconductors
}

\author{
A. Kovalgin, F. Chabert-Rocabois, M. Hitchman, S. Shamlian, S. Alexandrov
}

\section{To cite this version:}

A. Kovalgin, F. Chabert-Rocabois, M. Hitchman, S. Shamlian, S. Alexandrov. A study by In Situ FTIR Spectroscopy of the Decomposition of Precursors for the MOCVD of High Temperature Superconductors. Journal de Physique IV Proceedings, 1995, 05 (C5), pp.C5-357-C5-364. 10.1051/jphyscol:1995542 。 jpa-00253869

HAL Id: jpa-00253869 https://hal.science/jpa-00253869

Submitted on 1 Jan 1995

HAL is a multi-disciplinary open access archive for the deposit and dissemination of scientific research documents, whether they are published or not. The documents may come from teaching and research institutions in France or abroad, or from public or private research centers.
L'archive ouverte pluridisciplinaire HAL, est destinée au dépôt et à la diffusion de documents scientifiques de niveau recherche, publiés ou non, émanant des établissements d'enseignement et de recherche français ou étrangers, des laboratoires publics ou privés. 


\title{
A Study by In Situ FTIR Spectroscopy of the Decomposition of Precursors for the MOCVD of High Temperature Superconductors
}

\author{
A.Y. Kovalgin*, F. Chabert-Rocabois, M.L. Hitchman, S.H. Shamlian and S.E. Alexandrov* \\ Department of Pure and Applied Chemistry, University of Strathclyde, 295 Cathedral Street, Glasgow G1 \\ $I X L, U . K$.
}

* Department of Electronic Material Technology, St Petersburg State Technical University, Polytechnical Street 29, St Petersburg 195 25I, Russia

\begin{abstract}
In this paper we report on a study by FTIR spectroscopy of the gas phase thermal decomposition of [Y(TMHD) 3], [Cu(TMHD) 2 ] and [Ba(TDFND) 2.tetraglyme] under a total pressure of 10 Tor, for a temperature range $200-650^{\circ} \mathrm{C}$, and in the absence and presence of oxygen. The variation of the decomposition characteristics for each of the complexes as a function of temperature, and as shown by changes in the absorption coefficients, are related to the molecular structures.
\end{abstract}

\section{INTRODUCTION}

The $\beta$-diketonates of yttrium, barium and copper are of great interest for their application in the production of high temperature superconductor (HTS) films [1]. Metal complexes of HTMHD (where TMHD $=2,2,6,6$-tetramethylheptane-3,5-dione) are frequently used as precursors, especially the complexes [Y(TMHD) 3 ] and [Cu(TMHD) 2 ] because of their good volatility and stability. For barium, however, no such stable volatile precursor was available [1] until recently. Now several have been reported [2-5], one of which is [Ba(TDFND) 2.tetraglyme] [3,4] (where TDFND = $1,1,1,2,2,3,3,7,7,8,8,9,9,9$-tetradecafluorononane-4,6-dione).

If careful control of the properties and quality of HTS layers grown by MOCVD from such precursors is to be achieved, though, it is essential to try to understand the factors affecting film growth. Little has been reported, however, on the thermal decomposition of any of these compounds, especially in the presence of oxygen which is necessary for the growth of HTS layers. The only studies which have been carried out have been by mass spectroscopy for the thermal decomposition of [Cu(TMHD) 2 ] and [Y(TMHD) 3] [6-8]. In situ FTIR spectroscopy would be a useful complementary technique since it would probe the decomposition directly in the reactor and at the same time give information about bonding changes. Also it does not suffer from some of the disadvantages of mass spectroscopy, such as sampling difficulties, disturbance of the species in the gas phase, and blocking of an orifice. Therefore in order to try and obtain a better understanding of the chemical decomposition of [Y(TMHD) 3 ], $\left[\mathrm{Cu}(\mathrm{TMHD})_{2}\right]$ and [Ba(TDFND) 2 .tetraglyme], which we have previously used as precursors for the MOCVD of HTS thin films [3], we have begun a study by FTIR of their thermal decomposition in the gas phase in the absence and presence of oxygen under typical deposition conditions.

\section{EXPERIMENTAL}

The experimental arrangement used in this study is shown in Figure 1. It consisted of an FTIR spectrometer, a gas-handling facility, a reactor made up of an evaporator, a reactor tube and a thermostatted jacket, and a vacuum system. The FTIR spectrometer was a Mattson Research Series instrument with a EG\&G Judson HgCdTe detector (model: J15D 14-M1007-S01 M-45-005603). The gases used were nitrogen (BOC, silicon grade) and oxygen (Air Products, 99.6\%). The yttrium precursor (Inergtech. 99.9\%) and the copper precursor (Lancaster Synthesis, $99.1 \%$ ) were used as supplied without further purification. The barium precursor was provided hy The Associated Octel Co. Ltd. and was also used as received. The precursor heing studied was heated in a stanless sted evaporator. The temperature of the precursor was measured by a thermocouple situated on the top surlace of the precursor and 
temperatures of $132^{\circ} \mathrm{C}, 117^{\circ} \mathrm{C}$ and $125^{\circ} \mathrm{C}$ were used for [Y(THD) 3 ], [Cu(THD) $)_{2}$ ] and $\left[\mathrm{Ba}(\mathrm{TDFND})_{2}\right.$.tetraglyme], respectively: these are typical precursor temperatures for deposition of HTS layers [6]. The precursor vapour was carried to the reactor by a constant flow of $100 \mathrm{sccm}$ of nitrogen and to prevent condensation of the precursor before it reached the reactor the wall of the jacket was heated to $200^{\circ} \mathrm{C}$. For experiments with oxygen a constant flow of $40 \mathrm{sccm}$ through a side arm in the evaporator was used.

The reactor was made of quartz and had one inlet and two outlets. The diameter was $2.5 \mathrm{~cm}$ and the length was $27 \mathrm{~cm}$. The temperature range investigated in the reaction zone was $200-650^{\circ} \mathrm{C}$ and the total pressure was $1.33 \times 10^{3} \mathrm{~Pa}(10$ Torr). The temperature of the decomposition zone was monitored by a thermocouple placed centrally on the outside of the reactor tube, but this temperature was related to the temperature in the centre of the reaction tube by a calibration measurement made beforehand. The pressure was monitored with a Baratron gauge positioned in the exhaust line. The windows of the reactor tube were kept free from deposits by flushing with a flow of $80 \mathrm{sccm}$ of nitrogen.

Several spectra of the vapour in the decomposition zone were obtained at each temperature for the spectral region extending from $4500 \mathrm{~cm}^{-1}$ to $700 \mathrm{~cm}^{-1}$.

\section{RESULTS}

A typical spectrum for [Y(TMHD) 3] at $20\left(0^{\circ} \mathrm{C}\right.$ is shown in Figure 2. It is interesting to note the sensitivity of the FTIR instrument of about $0.01 \%$. Characteristic spectral bands for [Y(TMHD) 3 ] at $200^{\circ} \mathrm{C}$ appear at $2967 \mathrm{~cm}^{-1}$ which can be suggested to be due to the $\mathrm{C}-\mathrm{H}_{\mathrm{X}}$ stretch of the tertiary butyl groups, at 1571 . $1556 \mathrm{~cm}^{-1}$ arising from $\mathrm{C}=\mathrm{C}$ or $\mathrm{C}=\mathrm{O}$ stretching in the rings, and at $1508 \mathrm{~cm}^{-1}$ and $1408 \mathrm{~cm}^{-1}$ also due 10 ring $\mathrm{C}=\mathrm{C}$ stretching. The corresponding bands for $\left[\mathrm{Cu}(\mathrm{TMHD})_{2}\right]$ were at $2967 \mathrm{~cm}^{-1}$, at $1566-1553 \mathrm{~cm}^{-1}$. and at $1504 \mathrm{~cm}^{-1}$ and $1410 \mathrm{~cm}^{-1}$. For [Ba(TDFND)2 tetraglyme] characteristic spectral bands appeared at different frequencies. At $2913 \mathrm{~cm}^{-1}$ there was a band probably due to a $\mathrm{C}-\mathrm{H}_{\mathrm{X}}$ stretch in the tetraglyme: with bands at $1657 \mathrm{~cm}^{-1}$ and at $1517 \mathrm{~cm}^{-1}$ again due to ring $\mathrm{C}=\mathrm{C}$ or $\mathrm{C}=\mathrm{O}$ stretching, while at $1233 \mathrm{~cm}^{-1}$ there was a band which could be attributed to $\mathrm{C}-\mathrm{F}_{\mathrm{X}}$ stretching.

The absorption coefficient $(\alpha)$ was calculated from the relation

$\alpha=\left[\ln \left(\mathrm{I}_{0} / \mathrm{I}\right)\right] / \mathrm{d}$

where $I_{0}$ is the background intensity, $I$ the peak intensity and $d$ the length of the tube between the two $\mathrm{NaCl}$ windows. Values of the absorption coefficient normalised to the corresponding mean value obtained at $200^{\circ} \mathrm{C}$ are plotted as a function of temperature in Figures 3,4 and 5. In each case the partial pressure of the precursor giving rise to the signals could be estimated from its loss of weight during the time of the experiment. For [Y(TMHD) 3] the partial pressure was about $1.2 \mathrm{~Pa}$ in the absence of oxygen (Figure 3(a)), and about $0.8 \mathrm{~Pa}$ for an oxygen partial pressure of 380 Pa (Figure 3(b)). For [Cu(TMHD)1] the corresponding values were ca. $0.9 \mathrm{~Pa}$ (Figure $4(\mathrm{a})$ ) and ca. $0.5 \mathrm{~Pa}$ (Figure $4(\mathrm{~b})$ ), while for

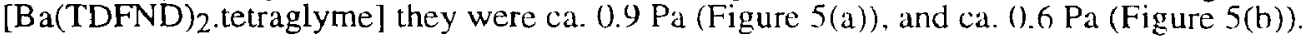

\section{1 [Y(TMHD) $\left.)_{3}\right]$}

Up to about $400^{\circ} \mathrm{C}$ and in the absence of oxygen the slight decrease of the relative absorption coefficicnt with temperature observed (Figure $3(\mathrm{a})$ ) is similar for the absorptions due to vibrations from both the ring and the ring substituents, $\mathrm{Bu}$. This variation mainly reflects the inverse dependence of the concentration. of a gas on temperature at constant total pressure. In the region 40()$-450^{\circ} \mathrm{C}$ the absorption arising from the $C=C$ and $C=O$ stretches begins to decrease slightly more rapidly than the absorptions attributed to the $\mathrm{C}-\mathrm{H}$ stretch. This suggests that the structure of the rings is less stable than the hydrocarbon moiety. The stability of the $\mathrm{C}-\mathrm{H}$ bonds is not surprising since it is well known 191 that thermal cracking of such bonds requires considerably higher temperatures than those used here. The appearance of a small peak at 2157 $\mathrm{cm}^{-1}$ indicating the formation of $\mathrm{CO}$ at temperatures above ca. $525^{\circ} \mathrm{C}$ is consistent with the breakup of the rings. Also this is not too unexpected if one compares the $\mathrm{Y}-\mathrm{O}$ bond length of $0.227 \mathrm{~nm} \mathrm{[10]} \mathrm{with} \mathrm{the}$ value of $0.230 \mathrm{~nm}$ expected on the basis of the appropriate ionic radii [11]; there clearly is not a strong orbital overlap and shortening and strengthening of the bond.

In the presence of oxygen, again up to about 40()$^{\circ} \mathrm{C}$ a similar variation of absorption coefficiont with temperature is observed for all the four main hands (Figure 3(b)). Above ca. $4\left(\right.$ ) " $^{\prime C}$ there is a much more dramatic decrease in the relative absorption coefficient with temperature and above ca. 570 " $\mathrm{C}$ none whe 
four initial vibrational modes can be detected. The appearance of a peak in the spectrum at $2367 \mathrm{~cm}^{-1}$ due to $\mathrm{CO}_{2}$ for temperatures $>450^{\circ} \mathrm{C}$, and reaching a constant value for temperatures greater than about $50(1)^{\circ} \mathrm{C}$. shows that uxidation of the entire organic structure is occurring, although again the hydrocarbon moicty seems to be slightly more resistant to decomposition than the rings.

The FTIR results presented here are in reasonable accord with the mass spectroscopic results of Bykov ct al. [7]. They found that in the absence of oxygen the precusor began to decompose at about $500^{\circ} \mathrm{C}$, which is only slightly higher than the region of $400-450^{\circ} \mathrm{C}$ where we observe the ring structures starting to break up. They also observed $\mathrm{CO}$ beginning to appear at ca. $550^{\circ} \mathrm{C}$, which is close to the temperature of $525^{\circ} \mathrm{C}$ mentioned above. Bykov et al. found that in the presence of oxygen decomposition started at about $400^{\circ} \mathrm{C}$ with practically no precursor signals left by ca. $600^{\circ} \mathrm{C}$ and with significant amounts of $\mathrm{CO}_{2}$ being detected for temperatures of $>400^{\circ} \mathrm{C}$. All these observations are in general agreement with those made here, with the FTIR results having the potential for yielding more information about the chemical changes occurring during decomposition of the precursors.

\section{3. $2\left[\mathrm{Cu}(\mathrm{TMHD})_{2}\right]$}

In the absence of oxygen there is a rather different hehaviour of the relative absorption coefficients with temperature for $\left[\mathrm{Cu}(\mathrm{TMHD})_{2}\right]$ (Figure 4(a)) compared with that seen for [Y(TMHD) 3 ]. Up to about $3(W)^{\prime \prime} \mathrm{C}$ the absurptions for both ring substituent and rings show a dependence of concentration on temperature, but above ca. $3000^{\circ} \mathrm{C}$ while there is only a continued slight fall off in the values for the $\mathrm{C}-\mathrm{H}$ stretch, similar to that observed in the case of [Y(TMHD) 3 , the values for the features associated with the rings drop dramatically. This indicates that for [Cu(TMHD) 2] the structure of the rings is less stable than for [Y(TMHD) 3], and this is consistent with the relative ionic characters of the $\mathrm{Y}-\mathrm{O}$ and $\mathrm{Cu}-\mathrm{O}$ bonds calculated on the basis of elemental electronegativities: the former has ca. $52 \%$ ionic character while the latter has only ca. 35\% and it is well known that an increase in polarity of a covalent bond strengthens the bond. The appearance of an absorption at $2157 \mathrm{~cm}^{-1}$ for $\mathrm{CO}$ for temperatures $>\mathrm{ca} .350^{\circ} \mathrm{C}$ again indicates break up of the ring structures. With oxygen present (Figure 4(b)) the tertiary butyl groups are also oxidised, although apparently more slowly than the rings. Above ca. $350^{\circ} \mathrm{C}$. $\mathrm{CO}_{2}$ was once more detected reaching a stable value above ca. $500^{\circ} \mathrm{C}$ when no further signals could be detected from the metallorganic complex.

Again a comparison can be made with the mass spectroscopic results of Bykov et al. [6]. They found that the onset of decomposition of the copper precursor without oxygen was at about $330^{\circ} \mathrm{C}$, which is in accord with our result (Figure $4(\mathrm{a})$ ). In addition they detected $\mathrm{CO}$ for temperatures $>330^{\circ} \mathrm{C}$, which also is in agreement with what we find. For the case with oxygen, the FTIR shows the onset of decomposition at about $250-30\left(0^{\circ} \mathrm{C}\right.$ (Figure $4(\mathrm{~b})$ ) which is exactly the same temperature region observed by Bykov et al. for the start of molecular degradation. They also saw a rapid build up of $\mathrm{CO}_{2}$ at temperatures $>325^{\circ} \mathrm{C}$, which is similar to our result.

\section{3 [Ba(TDFND) 2. tetraglyme]}

The barium complex is rather different from the yttrium and copper complexes, but it is still a $\beta$ diketonate and so one might expect its thermal decomposition behaviour to show some similarities to that observed for those two precursors. Indeed the trend of the $\mathrm{C}-\mathrm{H}$ absorption with temperature in the absence of oxygen (Figure 5(a)) is similar $\mathrm{to}$ that observed in the cases of the $\mathrm{Y}$ and $\mathrm{Cu}$ compounds even though for $\mathrm{Ba}$ the $\mathrm{C}-\mathrm{H}$ is associated with the polyether rather than with tertiary butyl ring substituents; the $\mathrm{C}-\mathrm{H}$ bond strengths in the two moieties would be expected to be comparable.

On the basis of electronegativities the $\mathrm{Ba}-\mathrm{O}$ bond has rather more ionic character (ca. $66 \%$ ) than either the $\mathrm{Y}-\mathrm{O}$ or $\mathrm{Cu}-\mathrm{O}$ bonds. Therefore one might expect the ring structures in the barium complex to be more resistant to breakup than in the case of either the ytrrium or copper complexes. A comparison of Figure $5(a)$ with Figures $3(a)$ and $4(a)$ suggests, though, an intermediate behaviour for the harium complex. This can be understood in terms of the strong clectron withdrawing inductive effect exerted by the highly electronegative lluorines leading to a low negative charge density on the oxygens in the rings and a tesulting lengthening and weakening of the $\mathrm{Ba}-\mathrm{O}$ bonds.

The hehaviour with temperature of the absorption due to the C-F bond suggests that there is some destruction of this rather strong bond. This appears at first sight to be a litte surprising, especially since 
the C-F bond energy is ca. $536 \mathrm{~kJ} \mathrm{~mol}^{-1}$ compared with a value of ca. $337 \mathrm{~kJ} \mathrm{~mol}^{-1}$ for a C-H bond [12]. However, preliminary mass spectroscopic results which we have obtained indicate that a $\mathrm{BaF}\left(\mathrm{CF}_{3}\right)$ unit is formed on thermolysis of the barium complex, presumably by the breaking off of a $\mathrm{CF}_{3}$ and linking to a $\mathrm{Ba}$ atom coupled with the possibility of the $\mathrm{Ba}$ at the same time bonding to a $\mathrm{F}$ atom in a sterically favourable position in the complex; the slightly stronger Ba-F bond - $587 \mathrm{~kJ} \mathrm{~mol}^{-1}$ [12] - would favour this.

In the presence of oxygen the disappearance of the ring structures and the C-F bonds follow similar trends with temperature as in the case without oxygen, although starting at lower temperatures because of the more oxidising conditions and the easier break up of the complex. The only surprising result with oxygen is the apparent stability of the $\mathrm{C}-\mathrm{H}$ bonds. However, there is a lot of scatter on this data, which was obtained from a rather small peak in the spectrum, and a repeat experiment has suggested that in fact the $\mathrm{C}-\mathrm{H}$ bond is destroyed by the oxygen; experiments are in progress to investigate this further.

\section{CONCLUSIONS}

The preliminary results presented here have shown that useful information can be obtained from in situ FTIR analysis of the decomposition of precursors used in the MOCVD of HTS thin films. The studies have revealed interesting differences between the thermolylic behaviour of the three precursors examined which can be understood in terms of the molecular structures of the complexes. We now propose to extend the studies to examining mixtures of the precursors and to attempt to relate the homogeneous gas phase chemistry to the heterogeneous deposition of HTS layers and to the effect of reaction parameters on layer properties.

\section{Acknowledgements}

This work was supported by the Commission of the European Communities under the BRITE/EURAM Programme, Contract No. BREU 0438.

\section{References}

[1] Hitchman M.L., Gilliland D.D., Cole-Hamilton D.J. and Thompson S.C., Inst. Phys. Conf. Ser., 111 (1990) 305-317

[2] Thompson S.C., Cole-Hamilton D.J., Gilliland D.D., Hitchman M.L. and Barnes J.C., Adv. Mater. Opt. Electron., 1 (1992) 81-97

[3] Shamlian S.H., Hitchman M.L., Cook S.L. and Richards B.C., J. Mater. Chem., 4 (1994) 81-85

[4] Hitchman M.L., Shamlian S.H., Gilliland D.D., Cole-Hamilton D.J., Nash J.A.P., Thompson S.C. and Cook S.L., J. Mater. Chem., 5 (1995) 47-52

[5] Timmer K., Spee K.I.M.A., Mackor A. and Meinema H.A., Inorg. Chim Acta, 190 (1992) 109-117

[6] Bykov A.F., Semyannikov P.P. and Igumenov K., J.Thermal Anal., 38 (1992) 1463-1475

[7] Bykov A.F., Semyannikov P.P. and Igumenov K., J.Thermal Anal., 38 (1992) 1477-1486

[8] Girolami G.S., Jeffries P.M. and Dubois L.H., J. Am. Chem. Soc., 115 (1993) 1015-1024

[9] Wiseman P., An Introduction to Industrial Organic Chemistry (Applied Science Publishers, London, 1979) p. 69

[10] Rees W.S., Luten H.A., Carris M.W., Doskocil E.J. and Goedken V.L., MRS Symp. Proc., 1992, 141

[11] Greenwood N.N. and Earnshaw A., Chemistry of the Elements (Pergamon Press, Oxford, 1984) p. 1497

[12] Weast R.C., Ed., CRC Handbook of Chemistry and Physics (CRC Press Inc., Boca Raton, Florida, 1979) p. F219 


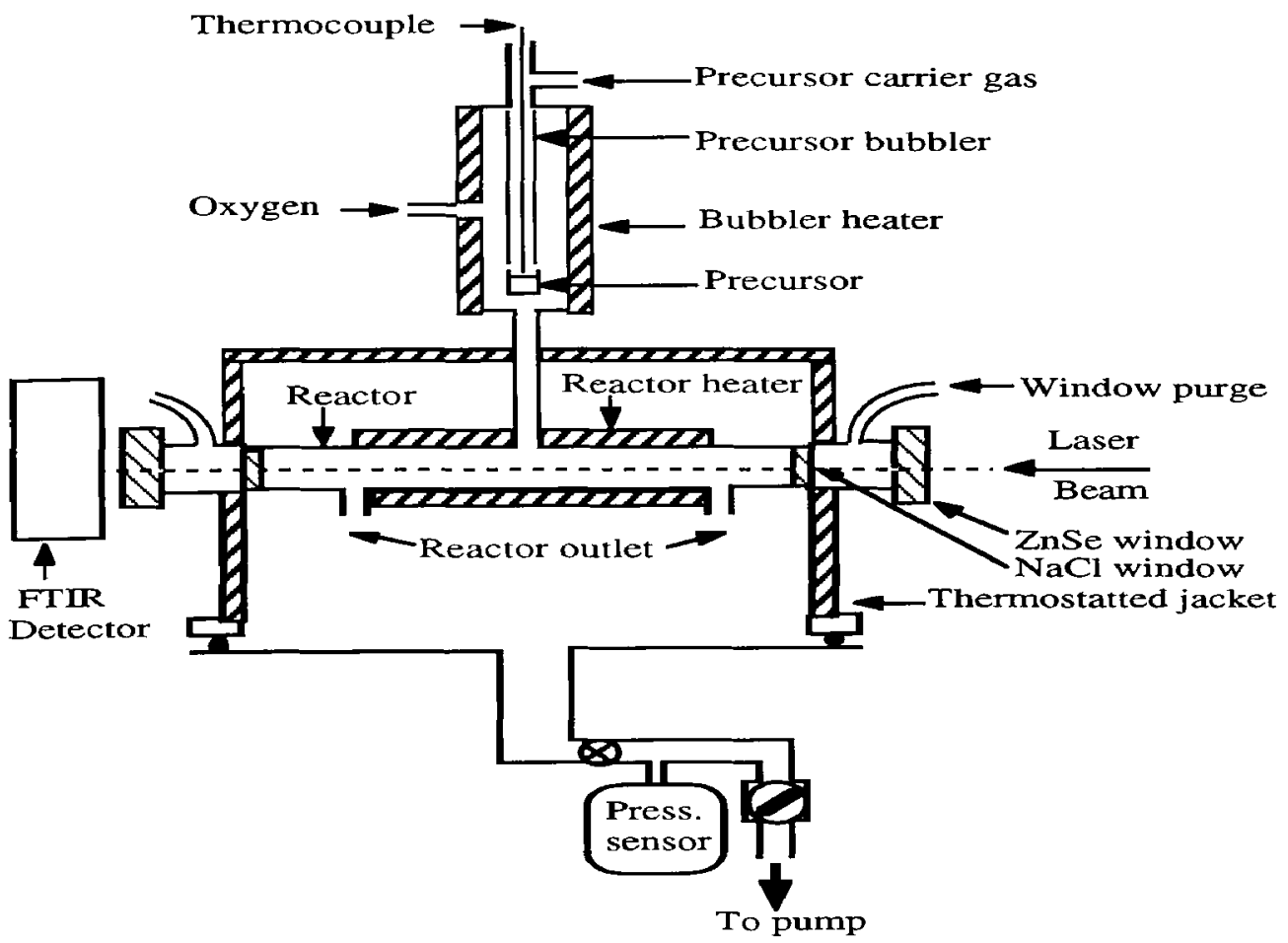

Figure 1: Diagram of the experimental arrangement

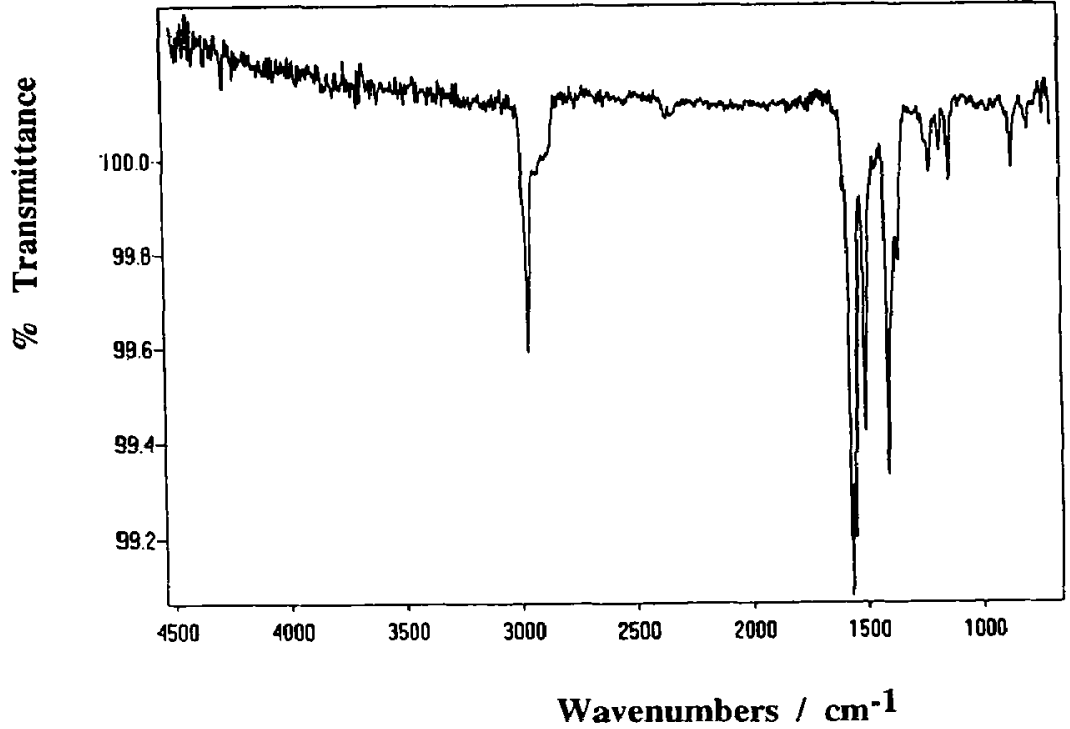

Figure 2: Typical spectrum of [Y(TMHD $\left.)_{3}\right]$ 

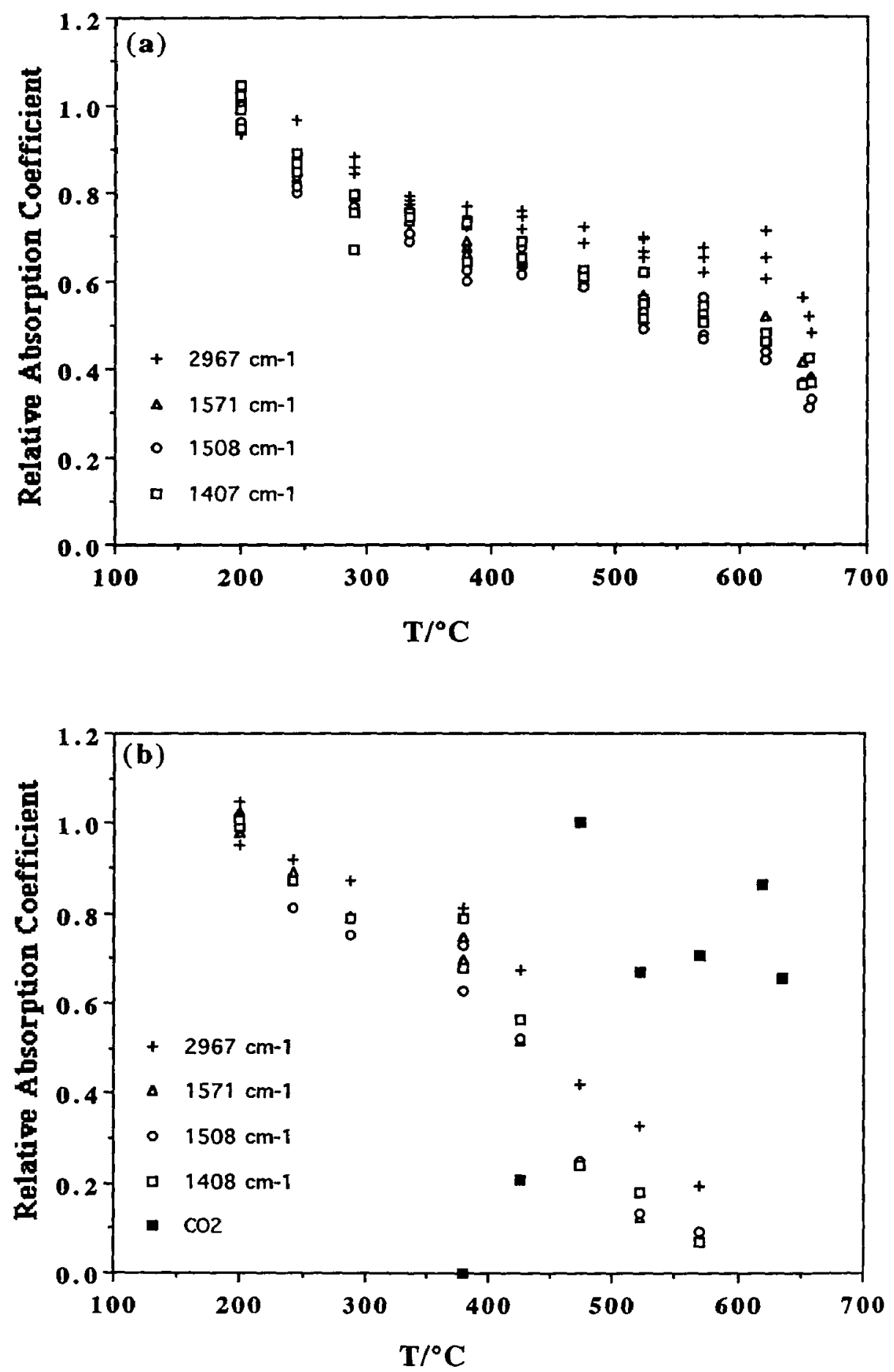

Figure 3: Plots of relative absorption coeflicients as a function of temperature for [Y(TMHD) 3 ] tapesur under a tolal pressure of $1.33 \times 30^{3} \mathrm{~Pa}$ ( 1 () Torr) (a) withoul oxygen and (b) with oxygen 

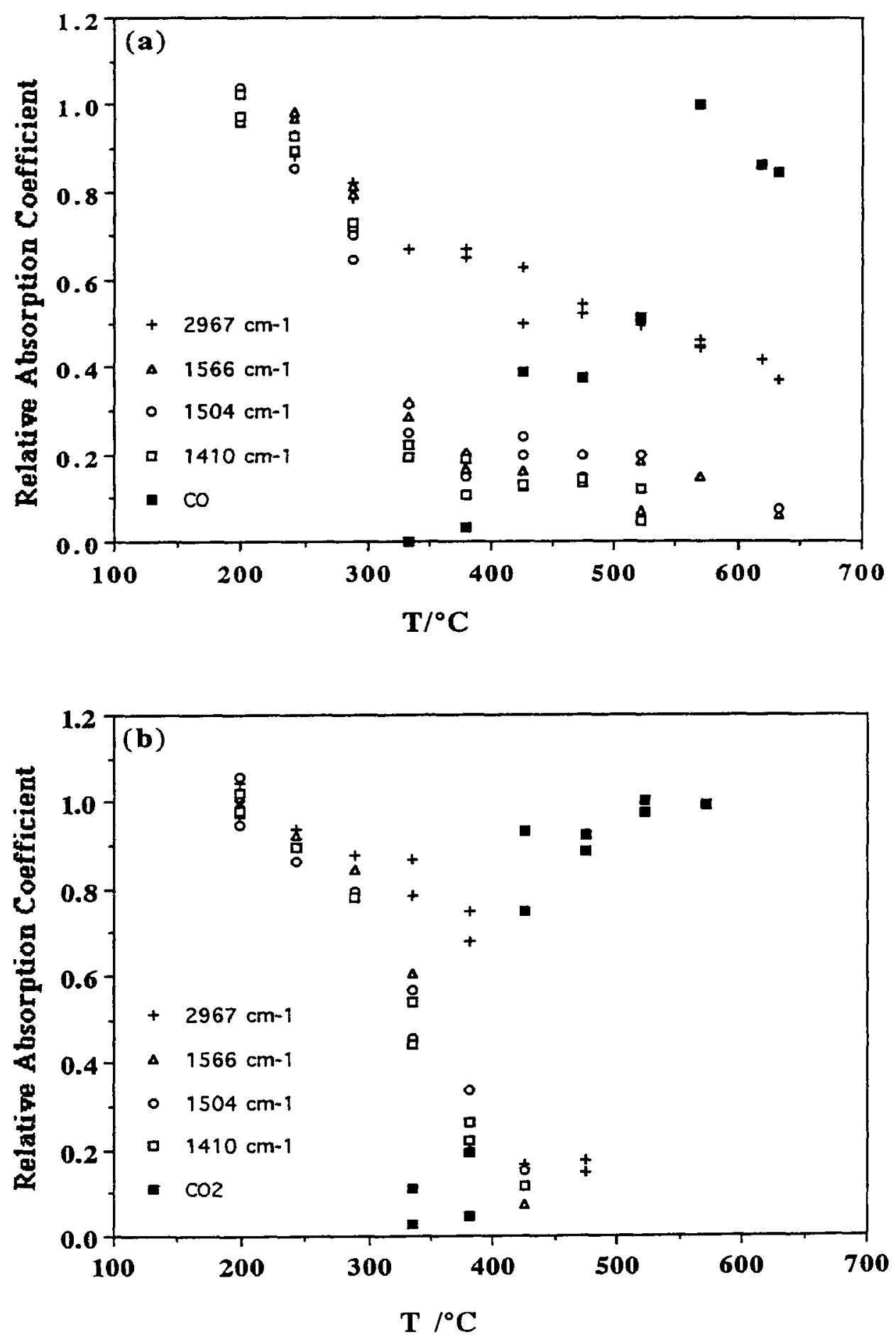

Figure 4: Plots of relative absorption coefficients as a function of temperature for [CurTMHD) 2 ] vapour under a total

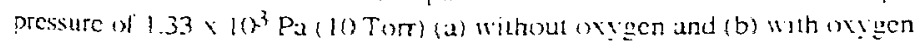



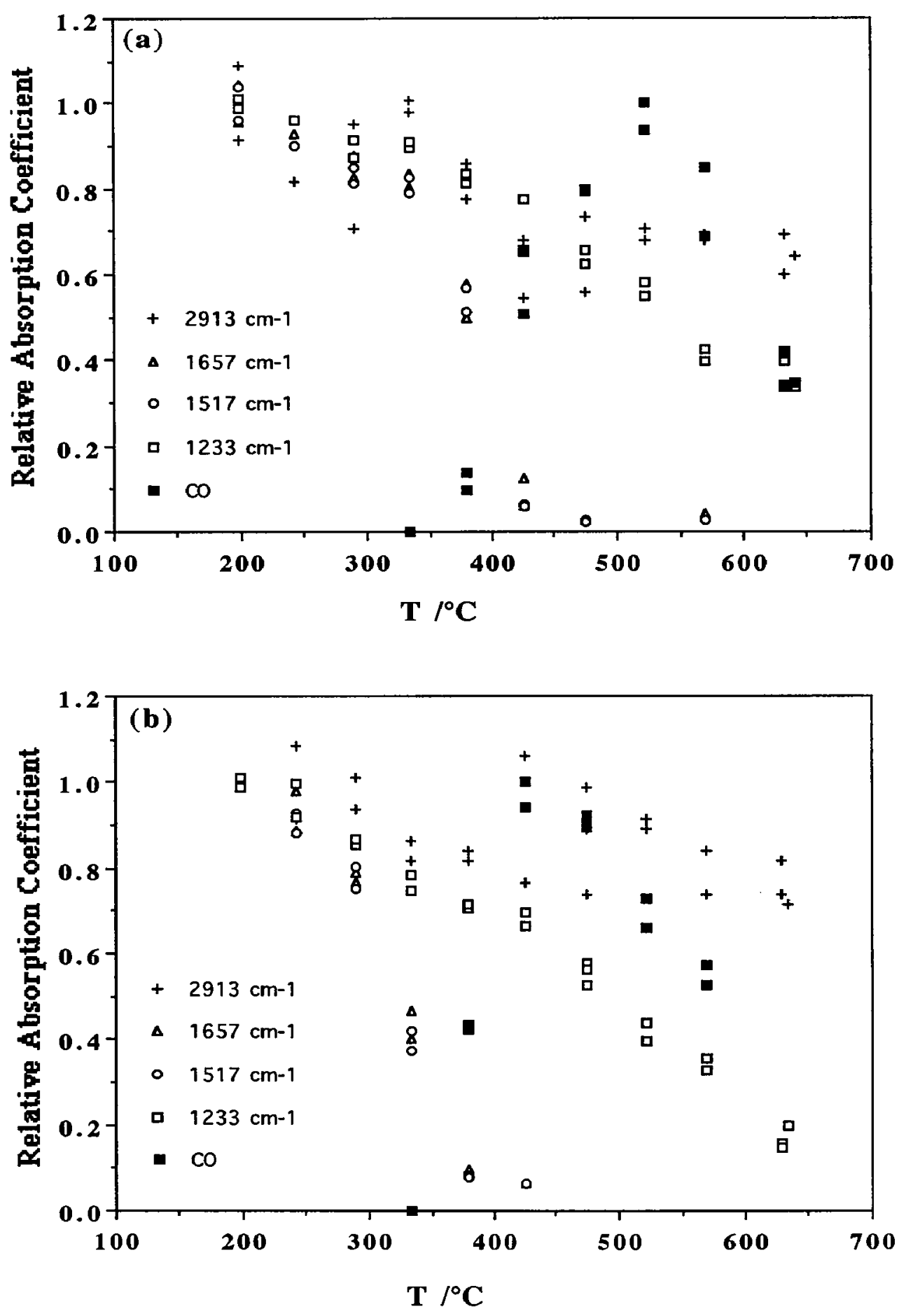

Figure 5: Plots of relative absorption cofficients as a function of temperiture for PBa(TDFND) 2 .tetraglymel $/$ apour under a tolal pressure of $1.33 \times 10^{3} \mathrm{~Pa}(10 \mathrm{Torr})(\mathrm{a})$ without oxygen and (b) with oxygen 